\title{
Insulin-like growth factor-1 and binding protein-3 in a 2-year soya intervention among premenopausal women
}

\author{
Gertraud Maskarinec ${ }^{1 *}$, Yumie Takata ${ }^{1}$, Suzanne P. Murphy ${ }^{1}$, Adrian A. Franke ${ }^{1}$ and Rudolph Kaaks ${ }^{2}$ \\ ${ }^{1}$ Cancer Research Center of Hawaii, 1236 Lauhala Street, Honolulu, HI 96813, USA \\ ${ }^{2}$ International Agency for Research on Cancer, Lyon, France
}

(Received 26 November 2004 - Revised 13 May 2005 - Accepted 14 May 2005)

\begin{abstract}
Soya foods may protect against the development of breast cancer. Insulin-like growth factor (IGF)-1 is under investigation as a possible link between nutrition and cancer. We examined the effect of soya foods on circulating IGF-1 and IGF binding protein (BP)-3 levels among 196 healthy premenopausal women in a 2-year randomised nutritional trial. The intervention group consumed two daily servings of soya foods including tofu, soya milk, soya nuts and soya protein powder (equivalent to $50 \mathrm{mg}$ isoflavones and $5-22 \mathrm{~g}$ soya protein per serving); the controls maintained their regular diet. Five serum samples at baseline, 3, 6, 12, and 24 months were collected in the morning during the luteal phase and analysed for IGF-1 and IGFBP-3 by double-antibody ELISA. We applied mixed models to investigate the intervention effect and predictors of serum levels while considering the repeated measurement design. Adherence with the study regimen was high and dropout rates were acceptable. Randomisation resulted in similar mean IGF-1 and IGFBP-3 levels by group. We did not observe a significant intervention effect on IGF-1, IGFBP-3, and their molar ratio during the entire study period. However, urinary isoflavone excretion during the study period was positively associated with IGF-1 $(P=0.04)$ and the IGF-1:IGFBP-3 ratio $(P=0 \cdot 06)$. The effect was consistent over time. Adding soya foods to the diet of premenopausal women does not appear to lower serum levels of IGF-1 and IGFBP-3; if anything, the greater protein intake from soya may lead to a small increase in IGF-1 serum levels.
\end{abstract}

Soya: Interventions: Insulin-like growth factor: Premenopausal women: Ethnicity

Soya foods may protect against the development of breast cancer as shown in several epidemiological studies (Dai et al. 2001; Wu et al. 2002b; Yamamoto et al. 2003), although negative results have also been reported (Yuan et al. 1995; Key et al. 1999). Insulin-like growth factor (IGF)-1 is under investigation as a possible link between nutrition and cancer development (Kaaks, 1996). IGF-1 plays a central role in regulating cell proliferation, differentiation and apoptosis in relation to nutritional status, and increased IGF-1 activity may predispose to cancer. Six IGF-binding proteins (BP) bind the majority of plasma IGF-1 and modulate its action (Yu \& Rohan, 2000). The mitogenic effect of higher IGF-1 levels and the stimulating effect of steroid hormones on breast cells may increase breast cancer risk (Holly, 1998). As reviewed by Renehan et al. (2004), there is evidence to support an association of elevated serum IGF-1, either as absolute concentrations or relative to levels of IGFBP-3, with breast cancer risk among women of premenopausal age.

Diet has increasingly been explored as a determinant of IGF-1 and IGFPB-3 levels, but only a few foods or nutrients have shown associations. Milk and fish consumption were directly related to IGF-1 in some studies (Holmes et al. 2002; Giovannucci et al. 2003), and in one previous study we also observed weak trends of higher IGF-1 levels with increasing intakes of grains, red meat, legumes, and fruit intake, and higher IGFBP-3 levels with increasing levels of grains, legumes, and fat and oils (Maskarinec et al. 2005). Three cross-sectional studies, one among premenopausal women in Japan (Nagata et al. 2003), one among British meat-eaters and vegetarians (Allen et al. 2002) and one among Dutch women (Vrieling et al. 2004), showed no significant association between soya food intake and IGF-1 levels. To date, four intervention studies have been conducted to examine the possible association between soya intake and IGF-1 levels. An intervention among pre- and postmenopausal women (Wangen et al. 2000) did not observe a consistent effect of soya supplementation, despite some small changes in IGF-1. During a 1-year soya trial, levels of IGF-1 and IGFBP-3 and their ratio did not change among men and women (Adams et al. 2003). However, a 3-month soya intervention significantly increased IGF-1 levels among healthy men consuming a soya protein drink (Khalil et al. 2002). In a 3-month trial using soya protein or milk-based protein supplementation, IGF-1 levels increased over time in both groups of postmenopausal women (Arjmandi et al. 2003). Given that hormone replacement therapy (Chang et al. 2002) and tamoxifen (Decensi et al. 1998) lower IGF-1 levels, we hypothesised that the oestrogen-like isoflavones in soya may have a similar effect. As part of a randomised trial among premenopausal women, we examined the effect of two daily servings of soya foods on circulating IGF-1 and IGFBP-3 levels and their ratio and explored possible predictors of IGF-1 and IGFBP-3 and their ratio. 


\section{Methods}

Study design

In a 2-year randomised trial among premenopausal women aged $34-47$ years, the intervention group consumed two daily servings of tofu, soya milk, soya nuts, soya bars, or soya protein powder provided at no cost to the subjects (Table 1). Women in the intervention group were individually counselled by a registered dietitian how to replace dairy, meat, or snack foods with soya foods; women in the control group maintained their regular diet. All participants were recruited through mailed invitations from mammographic screening clinics on the island of Oahu. Eligible women for the present study had a normal screening mammogram and regular menstrual cycles. Women on hormonal medication, with a previous diagnosis of cancer and those consuming more than seven servings of soya were excluded. This intervention study was approved by the Committee on Human Studies at the University of Hawaii and the Institutional Review Boards of the participating clinics. Details of the recruitment strategy and study procedures have been described elsewhere (Maskarinec et al. $2003,2004 a, b)$. According to seven unannounced $24 \mathrm{~h}$ recalls, mean daily soya intake was more than ten-fold higher in the intervention than in the control group; the high adherence was confirmed by urinary isoflavone excretion (Maskarinec et al. 2003). The dropout rates were similar in both arms of the trial; $15.6 \%$ for intervention subjects and $12.6 \%$ for controls. Although we randomised 220 women for this trial, a baseline and at least one follow-up IGF-1 measurement was available for 196 women and five IGF-1 measurements were available for 144 women only (n 196, 178, 182, 184 and 175 for baseline, 3, 6, 12 and 24 months, respectively).

\section{Data collection}

As part of the trial, we collected five blood and urine samples at baseline, 3, 6, 12 and 24 months. The samples were put immediately on ice, centrifuged, and serum was drawn off and sampled, and stored at $-80^{\circ} \mathrm{C}$. The blood draws were timed to day 19 of the ovulatory cycle or approximately $5 \mathrm{~d}$ after ovulation as detected by an ovulation kit (Maskarinec et al. 2004a). The baseline food-frequency questionnaire included questions about socio-demographic characteristics, physical activity, reproductive behaviour, and medical history. Body weight and height were measured at baseline and the end of the study. Levels of soya intake during early life and adulthood were estimated from a semi-quantitative lifetime soya-frequency questionnaire that asked about intake during childhood, adolescence, and early and late adulthood (Maskarinec et al. 2004b).

Table 1. Nutritional content of soya foods for the intervention

\begin{tabular}{|c|c|c|c|c|c|}
\hline \multirow[b]{2}{*}{ Soya food } & \multirow{2}{*}{$\begin{array}{l}\text { Serving size } \\
\text { (g) }\end{array}$} & \multicolumn{2}{|c|}{ Energy } & \multirow{2}{*}{$\begin{array}{l}\text { Protein } \\
\text { (g) }\end{array}$} & \multirow{2}{*}{$\begin{array}{l}\text { Isoflavones } \\
\qquad(\mathrm{mg})^{*}\end{array}$} \\
\hline & & $\mathrm{kJ}$ & kcal & & \\
\hline Tofu & 126 & 310 & 74 & 7.5 & $25 \cdot 1$ \\
\hline Soya milk & 180 & 406 & 97 & $4 \cdot 7$ & $27 \cdot 2$ \\
\hline Roasted soya nuts & 23 & 460 & 110 & $8 \cdot 2$ & $25 \cdot 6$ \\
\hline Soya protein powder & 31 & 418 & 100 & $21 \cdot 9$ & $26 \cdot 4$ \\
\hline Soya protein bars & 58 & 669 & 160 & $10 \cdot 9$ & $19 \cdot 8$ \\
\hline
\end{tabular}

* Analysed by the Analytical Laboratory at the Cancer Research Center of Hawaii.

\section{Analytical methods}

IGF-1 and IGFBP-3 were measured by double-antibody ELISA assays (Diagnostic Systems Laboratories, Webster, TX, USA) (Kaaks et al. 2000). All samples from one subject were analysed in the same batch. The batches were assembled with an equal number of intervention and control samples and, whenever possible, balanced according to ethnicity and age. There were three ways of assessing the quality of measurements. According to laboratory standards, the respective ranges of intra-batch correlation coefficients (CV) for IGF-1 and IGFBP-3 were $3 \cdot 1-5 \cdot 3 \%$ and $4 \cdot 1-5.6 \%$, whereas inter-batch $\mathrm{CV}$ ranges were $12 \cdot 5-16 \cdot 1 \%$ and $5 \cdot 0-5.8 \%$, respectively. Based on sixty blind quality controls from a pooled serum sample, the inter-batch CV for IGF-1 and IGFBP-3 levels were 15.4 and $10 \cdot 2 \%$, respectively. Finally, baseline measurements for both analytes had been performed some time ago using the same methodology (Maskarinec et al. 2005); the Pearson correlation coefficients for the values of the 193 women in both datasets were 0.82 for IGF-1 and 0.73 for IGFBP-3 indicating high reproducibility of our measurements. The IGF-1:IGFBP-3 molar ratio was calculated by converting IGF-1 and IGFBP-3 values from $\mathrm{ng} / \mathrm{ml}$ to $\mathrm{nmol}$ using the factors of 0.13 and 0.035 , respectively. The soya isoflavones and their metabolites were measured in urine by high-pressure liquid chromatography with photodiode array detection and included genistein, dihydrogenistein, daidzein, dihydrodaidzein, glycitein and $O$-desmethylangolensin. Equol was also measured with this method but with lower sensitivity than the other isoflavonoids. The sum of these analytes was expressed as total urinary isoflavonoid excretion rate per $\mathrm{mg}$ creatinine units $(\mathrm{nmol} / \mathrm{mg}$ ) as a specific marker for soya consumption (Maskarinec et al. 1998, 2003). In agreement with our previous classification for compliers (Maskarinec et al. 2004a), we considered less than $4 \mathrm{nmol} / \mathrm{mg}$ creatinine as low isoflavone exposure and values of $4 \mathrm{nmol} / \mathrm{mg}$ creatinine and above as high isoflavone exposure.

\section{Statistical analysis}

Based on the lifetime soya consumption questionnaire (Maskarinec et al. 2004b), previous soya intake was calculated for early life (1-19 years) and adulthood (over age 20 years) by computing the mean annual intake in number of servings. The reported intake was categorised into none $v$. any intake during early life and into low $v$. high during adult life with a cut-off of thirty-six servings per year. Body weight was measured at baseline and at the end of the study; we calculated the BMI at these times and performed linear interpolation for months 3,6 , and 12 . Physical activity level (PAL) was calculated from the participant's baseline report of daily activity; hours spent on sleeping, sitting, moderate, vigorous and strenuous activities and divided into low and high PAL at 1.42. The participants reported all ethnic backgrounds for themselves and their parents. On the basis of this, we classified participants according to the following rules. If both parents reported Caucasian background and no other common ethnic background, a woman was classified as Caucasian. For a participant who reported no more than three ethnic backgrounds, if both parents were of Asian ancestry or if the mother was of Asian ancestry and the parents reported no other common ethnic background, she was classified as Asian. 'Other' category included Pacific Islanders, African-Americans, Latinos and women of mixed ethnic background. 
All statistical analyses were performed with the SAS software package (SAS Institute Inc., Cary, NC, USA). For continuous variables, Student's $t$ tests were performed to examine difference in baseline characteristics between the control and intervention groups. For categorical variables, $\chi^{2}$ tests were used instead. We applied mixed models to test for an intervention effect while taking into account the repeated measurement design with the option of autoregressive order 1 covariance structure (SAS Institute Inc., 2002) because measurements are less correlated when further apart in time. For post hoc analyses, women were stratified by childhood and adult soya consumption, physical activity level, ethnicity, and BMI. We also repeated the overall analysis by low $v$. high isoflavone excretion instead of group assignment since this may be a better indicator of actual isoflavone exposure. To explore determinants of IGF-1 and IGFBP-3, we entered the following covariates into the mixed models while retaining the time variable: urinary isoflavone excretion as a continuous variable (coded $1-5$ for $0,<3,3-15,15-45$, and $45+\mathrm{nmol} / \mathrm{mg}$ creatinine, respectively), ethnicity, BMI, ever pregnant, age at first live birth, soya intake during early life and adulthood, and PAL at the time of the blood draws. Due to the narrow age range of our population, age was not related to the serum measurements and was not included into any model.

\section{Results}

Of the 196 women in this analysis, more than half reported non-Caucasian ancestry (Table 2). The two groups were very similar in demographic, anthropometric, reproductive, and nutritional characteristics, as well as IGF-1, IGFBP-3, and their molar ratio. Both groups increased their weight during the trial, but there was no difference between groups $(0.62 \mathrm{~kg}$ for controls $v .1 .07 \mathrm{~kg}$ for intervention subjects; $P=0.44$ ). The proportion of women who consumed before the trial did not vary by experimental group; the respective proportion of early-life and adulthood soya consumers were 51.5 v. $48.5 \%$ and $80.8 v .84 .5 \%$ for the control and intervention groups, respectively. When stratified by Asian ethnicity, the proportion of early-life soya consumers was $26.1 \%$ for non-Asians and $87.0 \%$ for Asians. The respective proportions for adulthood were 76.5 and $92.2 \%$. Protein intake measured at baseline was similar in the control (15.2 (SD 2.8) \%) and intervention (15.1 (SD 2.4) \%) groups, but during the first study year it was higher among women eating soya (16.7 (SD 3.1) \% v. 18.9 (SD 4.2) $\% ; P<0.0001$ ). At baseline, the respective IGF1 values for Caucasians, Asians and others were 315.9, 324.0, and $330.3 \mathrm{ng} / \mathrm{ml}$ for IGF-1 $(P=0.53)$; IGFBP-3 levels were 4375,4390 , and $4259 \mathrm{ng} / \mathrm{ml}(P=0.54)$ and the IGF-1:IGFBP-3 ratio was $0 \cdot 268,0.277$, and $0.291(P=0.056)$.

We observed no significant difference by group assignment for IGF-1, IGFBP-3, and their molar ratio (Fig. 1), although IGF-1 levels were 18 and $13 \mathrm{ng} / \mathrm{ml}$ higher among the intervention than the control group at month 3 and 6; the respective $P$ values for group effect were $0.36,0.06$, and 0.92 . The slightly lower IGFBP-3 levels among controls throughout the study period were not a result of the intervention as indicated by the lack of a significant interaction effect between experimental group and time. Both IGF-1 and IGFBP-3 and their ratio were quite stable over time $(P=0.99,0.82$, and 0.87$)$. The mean

Table 2. Baseline characteristics of experimental groups (Mean values and standard deviations)

\begin{tabular}{|c|c|c|c|c|c|}
\hline \multirow[b]{2}{*}{ Characteristics } & \multicolumn{2}{|c|}{ Control group ( $n$ 99) } & \multicolumn{2}{|c|}{ Intervention group ( $n$ 97) } & \multirow[b]{2}{*}{$P$ values* } \\
\hline & Mean & SD & Mean & SD & \\
\hline Ethnicity & & & & & 0.84 \\
\hline Caucasian: $n$ & 37 & & 35 & & \\
\hline$\%$ & $37 \cdot 4$ & & $36 \cdot 1$ & & \\
\hline Asian: $n$ & 40 & & 37 & & \\
\hline$\%$ & $40 \cdot 4$ & & $38 \cdot 1$ & & \\
\hline Other: $n$ & 22 & & 25 & & \\
\hline$\%$ & $22 \cdot 2$ & & $25 \cdot 8$ & & \\
\hline Age (years) & $42 \cdot 8$ & $2 \cdot 9$ & $43 \cdot 3$ & $2 \cdot 8$ & $0 \cdot 20$ \\
\hline Born in the USA (\%) & $91 \cdot 8$ & & $90 \cdot 7$ & & 0.80 \\
\hline Family history of breast cancer (\%) & $13 \cdot 3$ & & $17 \cdot 9$ & & 0.37 \\
\hline Age at first live birth (years) & $27 \cdot 4$ & $5 \cdot 7$ & $28 \cdot 7$ & $5 \cdot 2$ & $0 \cdot 16$ \\
\hline Number of children & $1 \cdot 7$ & $1 \cdot 6$ & $1 \cdot 7$ & $1 \cdot 2$ & $0 \cdot 84$ \\
\hline Age at menarche (years) & $12 \cdot 8$ & $1 \cdot 3$ & $12 \cdot 9$ & 1.4 & 0.80 \\
\hline Body weight (kg) & $68 \cdot 2$ & $17 \cdot 3$ & 68.9 & $16 \cdot 4$ & 0.76 \\
\hline BMI $\left(\mathrm{kg} / \mathrm{m}^{2}\right)$ & $26 \cdot 0$ & $6 \cdot 0$ & $26 \cdot 4$ & $5 \cdot 7$ & 0.62 \\
\hline Physical activity level† & 1.47 & 0.15 & 1.49 & 0.26 & 0.50 \\
\hline \multicolumn{6}{|l|}{ Soya consumption (servings/year) } \\
\hline Early life ( $<20$ years) & $43 \cdot 5$ & $75 \cdot 4$ & $30 \cdot 0$ & $49 \cdot 8$ & $0 \cdot 14$ \\
\hline Adulthood (20 + years) & 64.9 & $81 \cdot 2$ & $56 \cdot 0$ & $71 \cdot 6$ & 0.42 \\
\hline Urinary isoflavones (nmol/mg creatinine) & $5 \cdot 5$ & $14 \cdot 9$ & $8 \cdot 1$ & $18 \cdot 3$ & 0.28 \\
\hline IGF-1 (ng/ml) & $323 \cdot 2$ & 73.7 & 321.9 & $65 \cdot 3$ & 0.90 \\
\hline IGFBP-3 (ng/ml) & 4295 & 608 & 4413 & 724 & $0 \cdot 22$ \\
\hline IGF-1:IGFBP-3 ratio & 0.28 & 0.05 & 0.27 & 0.05 & 0.38 \\
\hline
\end{tabular}

IGF, insulin-like growth factor; BP, binding protein.

${ }^{*} P$ values are based on a comparison between the control and intervention group by $t$ test for numeric variables and $\chi^{2}$ test for categorical variables. †Physical activity level was calculated from the number of hours spent sleeping, sitting, and doing three different levels of physical activities reported from the questionnaire. 

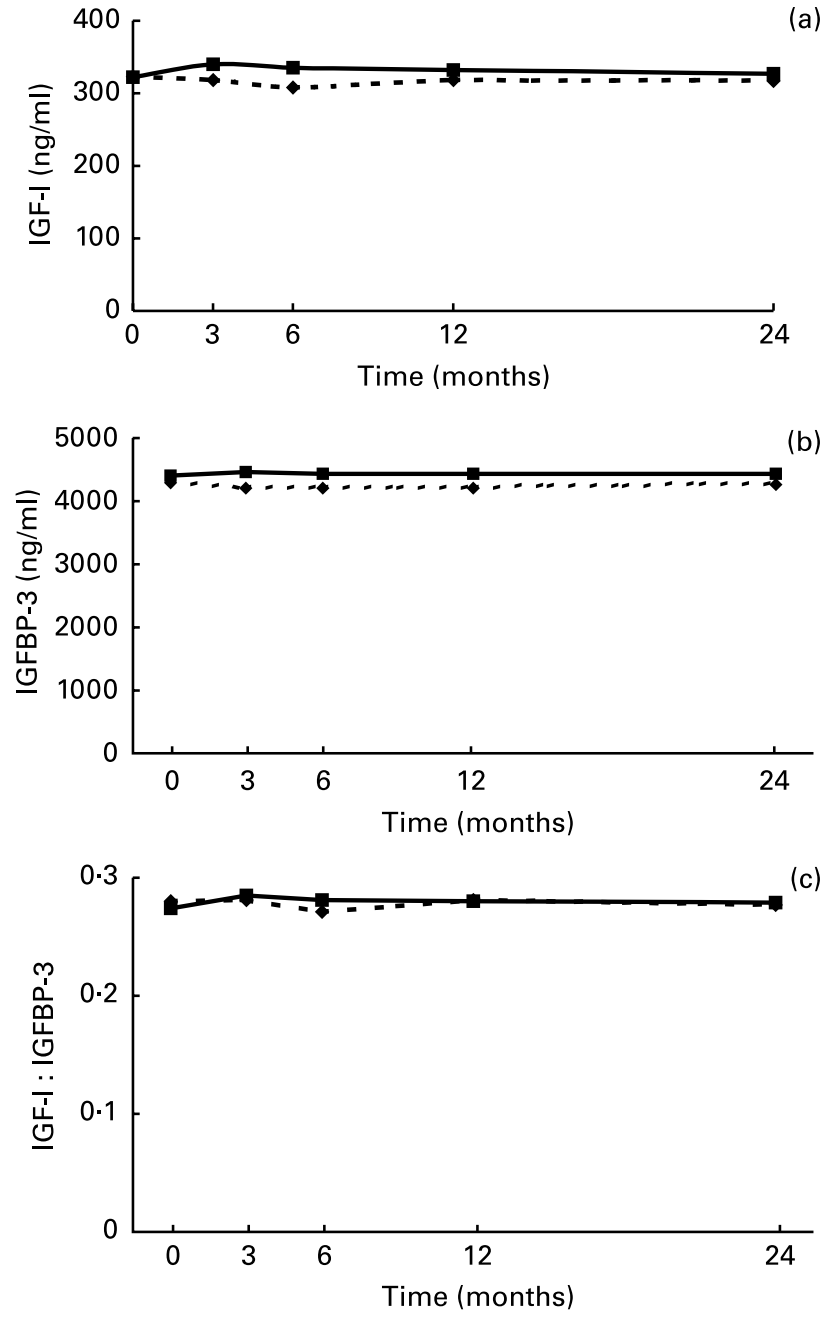

Fig. 1. (a) Insulin-like growth factor (IGF)-1 levels over time for control (- and intervention (- - ) groups; (b) IGF binding protein (BP)-3 levels over time by experimental group; (c) IGF-1:IGFBP-3 molar ratio over time by experimental group. Mean unadjusted levels per group were based on 196, 178, 182, 184 and 175 samples at baseline, 3, 6, 12, and 24 months, respectively. annual changes during the study period for control and intervention women were minimal: 0.85 v. $1.54 \mathrm{ng} / \mathrm{ml}$ for IGF-1, $-63.3 v$. $-14.6 \mathrm{ng} / \mathrm{ml}$ for IGFBP-3, and 0.003 v. 0.002 for the molar ratio. The stability of IGF-1 and IGFBP-3 levels during the 2-year study period was also apparent in the high intraclass correlation coefficients of 70.7 and $73.0 \%$ for IGF-1 and IGFBP-3, respectively.

Post hoc analyses exploring the possibility of an intervention effect after stratification by BMI, PAL, Asian ethnicity, earlylife and adult soya intake showed no significant findings in any of the subgroups (data not shown), although we observed small differences in serum levels between strata. Since urinary isoflavone excretion may be a better indicator of isoflavone exposure than group assignment, we repeated the analysis using a binary variable for urinary isoflavone excretion instead of experimental group. Women with high isoflavone excretion had significantly higher IGF-1 levels $(P=0.005)$ and there was no significant time effect. For the low exposure group, the five mean IGF-1 levels were $319,326,315,311$, and $317 \mathrm{ng} / \mathrm{ml}$, whereas the respective values for the high exposure group were 331, 333, 327,344 , and $329 \mathrm{ng} / \mathrm{ml}$. The respective numbers of women with low excretion at each time point were 145, 79, 96, 104, and 57 , while $50,105,91,86$, and 85 subjects excreted levels above $4 \mathrm{nmol} / \mathrm{mg}$ creatinine. We observed no significant differences in IGFBP-3 levels and the IGF-1:IGFBP-3 ratio when we applied this approach. In a mixed model that included all five measurements and IGFBP-3, we identified several significant determinants of serum IGF-1 levels in addition to urinary isoflavone levels (Table 3). A higher BMI, ever being pregnant, and an age of first live birth less than 30 years of age were related to lower IGF-1 levels and Hawaiian or mixed ethnicity predicted higher IGF-1 levels. Parous women had higher IGFBP-3 levels, but that was the only significant association for the binding protein. For the molar ratio, similar associations as for IGF-1 were observed, except that age at first live birth and urinary isoflavone excretion were not statistically significant anymore and soya intake during childhood was positively related to the IGF1:IGFBP-3 ratio. Adult soya consumption and PAL were not significantly related to any outcome measures.

Table 3. Association of insulin-like growth factor (IGF)-1, IGF binding protein (BP)-3, and the IGF-1:IGFBP-3 ratio with other variables *(Estimates and standard errors)

\begin{tabular}{|c|c|c|c|c|c|c|c|c|c|}
\hline \multirow[b]{2}{*}{ Variable } & \multicolumn{3}{|c|}{ IGF-1 (ng/ml) } & \multicolumn{3}{|c|}{ IGFBP-3 (ng/ml) } & \multicolumn{3}{|c|}{ IGF-1: IGFBP-3 ratio } \\
\hline & Estimate & SE & $P$ & Estimate & SE & $P$ & Estimate & SE & $P$ \\
\hline Intercept & $162 \cdot 8$ & $24 \cdot 0$ & $<0.0001$ & $2784 \cdot 4$ & 233.3 & $<0.0001$ & 0.329 & 0.017 & $<0.0001$ \\
\hline Time (months) & -0.2 & 0.3 & 0.56 & 1.9 & $2 \cdot 5$ & 0.43 & 0.000 & 0.000 & 0.74 \\
\hline Urinary isoflavone excretion† & 2.6 & $1 \cdot 2$ & 0.04 & $-14 \cdot 7$ & 11.4 & 0.20 & 0.002 & 0.001 & 0.06 \\
\hline Hawaiian and mixed $v$. Caucasian & $21 \cdot 2$ & 8.5 & 0.01 & $-154 \cdot 2$ & $91 \cdot 5$ & 0.09 & 0.023 & 0.007 & 0.002 \\
\hline Asian v. Caucasian & $-5 \cdot 7$ & $9 \cdot 3$ & 0.54 & $41 \cdot 8$ & $99 \cdot 3$ & 0.67 & -0.003 & 0.008 & 0.68 \\
\hline BMI $\left(\mathrm{kg} / \mathrm{m}^{2}\right)$ & $-2 \cdot 1$ & 0.5 & $<0.0001$ & $5 \cdot 7$ & 5.9 & 0.34 & -0.002 & 0.000 & 0.0005 \\
\hline Ever pregnant & $-21 \cdot 3$ & 9.9 & 0.03 & $270 \cdot 3$ & $105 \cdot 3$ & 0.01 & -0.021 & 0.008 & 0.01 \\
\hline Age at first live birth $<30$ years & $-16 \cdot 0$ & $7 \cdot 0$ & 0.02 & -131.4 & $75 \cdot 2$ & 0.08 & -0.009 & 0.006 & $0 \cdot 13$ \\
\hline Soya during childhood (any $v$. none) & $12 \cdot 7$ & 8.4 & $0 \cdot 13$ & $-122 \cdot 3$ & $90 \cdot 4$ & $0 \cdot 18$ & 0.016 & 0.007 & 0.03 \\
\hline Soya during adulthood (high $v$. low) $\ddagger$ & $-9 \cdot 1$ & $6 \cdot 8$ & 0.18 & -29.9 & $73 \cdot 1$ & 0.68 & -0.008 & 0.006 & 0.19 \\
\hline Physical activity (high $v$. low)§ & $4 \cdot 1$ & $6 \cdot 3$ & 0.52 & -118.5 & $67 \cdot 8$ & 0.08 & 0.005 & 0.005 & 0.39 \\
\hline IGFBP-3 or IGF-1 (ng/ml) & 0.1 & 0.0 & $<0.0001$ & 4.5 & 0.3 & $<0.0001$ & $\mathrm{~N} / \mathrm{A}$ & N/A & $\mathrm{N} / \mathrm{A}$ \\
\hline
\end{tabular}

$\mathrm{N} / \mathrm{A}$, not applicable.

* All variables except serum analytes and urinary isoflavones were measured at baseline only.

$\dagger$ As a continuous variable coded $1-5$ representing $0,<3,3-15,15-45$, and $45+\mathrm{nmol} / \mathrm{mg}$ creatinine, respectively.

$\ddagger$ Cut-off is twenty-six servings per year.

§Cut-off is 1.42 . 


\section{Discussion}

In a 2-year soya intervention, levels of IGF-1, IGFBP-3 and their ratio did not change as the result of the nutritional modification. A small increase in IGF-1 during the first 6 months among women with high soya intake disappeared later on. There was also no indication that any subgroup experienced a modification in IGF1 or IGFB-3 levels as a result of the intervention. However, we observed a weak positive association between IGF-1 and actual soya intake as measured by urinary isoflavones during the 2year period. Self-reported levels of soya during the time before the trial showed little effect on any of the outcomes, except for a weak positive association of early-life soya intake with the IGF-1:IGFBP-3 ratio. Levels of IGF-1 and its binding protein remained quite stable during the 2-year study period independent of group status. The results of our quality-control analysis indicated very high reproducibility of the IGF-1 and the IGFBP-3 measurements.

The present soya intervention study is the largest and longest to date investigating IGF-1 levels. It is also the only study that used a choice of soya foods instead of a protein supplement; the four previous studies provided a soya protein drink containing $40 \mathrm{~g}$ soya protein to their participants. Our findings confirm those from a 1-year study among men and postmenopausal women (Adams et al. 2003) and from fourteen premenopausal women who were part of a larger intervention (Wangen et al. 2000). In contrast, two studies reported significantly higher IGF-1 levels after 3 months of soya supplementation (Khalil et al. 2002; Arjmandi et al. 2003). One possible explanation for these discrepant results is that the study populations in these two studies reacted to the very high additional protein intake of $40 \mathrm{~g}$. Although milk protein also led to somewhat higher levels of IGF-1, the amino acid composition of the soya protein may have had a stronger stimulating effect on IGF-1 production. A cross-sectional study among meat-eaters and vegetarians supports this idea (Allen et al. 2002); a moderate positive association between IGF-1 and intake of animal and soya protein was observed in that study. Our observations of slightly higher IGF-1 levels among intervention women than controls during the first 6 months of the trial and the positive association between urinary isoflavones may have also been the result of the slightly increased protein intake as shown by the $24 \mathrm{~h}$ recall data. The oral intake of oestrogens, in the form of postmenopausal replacement therapy, has been shown to reduce the hepatic synthesis and blood levels of IGF-1 (Campagnoli et al. 1999). It has been speculated that elevated intakes of phyto-oestrogens could have had the same effect, but this is clearly not supported by our data.

The direct association of the molar IGF-1:IGFBP-3 ratio with soya intake in early life would seem to contrast with observations from two case-control studies that reported a lower breast cancer risk for women consuming soya during adolescence (Shu et al. 2001; Wu et al. 2002a). However, the present results may well be due to chance, a result of errors in the self-reported soya intakes in the past, or an effect of residual confounding because higher soya intakes early in life were primarily reported by women of Japanese ancestry.

We have not had a chance to validate the lifetime soya questionnaire. Nevertheless, we have some confidence that women can be reliably classified into low and high soya consumers because of the distinct nature of soya foods. Limitations in our assessment tool may also be responsible for the lack of an association between PAL and IGF-1 levels as reported by other studies (for a review, see Yu \& Rohan, 2000), but null results have also been published (DeLellis et al. 2004). As in other nutritional trials, questions about adherence and standardisation of food intake remain and may limit the validity of our findings. The present results may not be generalisable to other populations; the subjects may have a higher risk of breast cancer than the general population because they were recruited from mammographic screening clinics. The strengths of the present study include five blood collections, highly reproducible serum measurements, successful randomisation, good compliance with the study regimen, a long intervention period, and a well-controlled blood collection.

In summary, results from the present randomised soya intervention provide strong evidence that adding soya foods to the diet of premenopausal women aged 34-47 years does not lower IGF-1 and IGFBP-3 levels. Given the previous evidence of higher IGF-1 levels as a result of soya supplementation (Khalil et al. 2002; Arjmandi et al. 2003) and our observation that higher IGF-1 levels were associated with soya intake as assessed by urinary isoflavone excretion, IGF-1 levels may increase slightly as a result of additional protein or another component in soya, but it is not clear at this time if the protein or the isoflavones contained in soya foods play a role.

\section{Acknowledgements}

This research was supported by grant no. 02A021 from the American Institute for Cancer Research and by grant R01 CA80843 from the National Cancer Institute. We are very grateful to the dedicated study participants. Also, we acknowledge the support through food donations from Aloha Tofu, Dr Soy, and The Solae Company.

\section{References}

Adams KF, Newton KM, Chen C, Emerson SS, Potter JD, White E \& Lampe JW (2003) Soy isoflavones do not modulate circulating insulin-like growth factor concentrations in an older population in an intervention trial. J Nutr 133, 1316-1319.

Allen NE, Appleby PN, Davey GK, Kaaks R, Rinaldi S \& Key TJ (2002) The associations of diet with serum insulin-like growth factor I and its main binding proteins in 292 women meat-eaters, vegetarians, and vegans. Cancer Epidemiol Biomarkers Prev 11, 1441-1448.

Arjmandi BH, Khalil DA, Smith BJ, Lucas EA, Juma S, Payton ME \& Wild RA (2003) Soy protein has a greater effect on bone in postmenopausal women not on hormone replacement therapy, as evidenced by reducing bone resorption and urinary calcium excretion. J Clin Endocrinol Metab 88, 1048-1054.

Campagnoli C, Ambroggio S, Biglia N \& Sismondi P (1999) Conjugated estrogens and breast cancer risk. Gynecol Endocrinol 13, Suppl. 6, $13-19$.

Chang S, Wu X, Yu H \& Spitz MR (2002) Plasma concentrations of insulin-like growth factors among healthy adult men and postmenopausal women: associations with body composition, lifestyle, and reproductive factors. Cancer Epidemiol Biomarkers Prev 11, 758-766.

Dai Q, Shu XO, Jin F, Potter JD, Kushi LH, Teas J, Gao YT \& Zheng W (2001) Population-based case-control study of soyfood intake and breast cancer risk in Shanghai. Br J Cancer 85, 372-378.

Decensi A, Bonanni B, Guerrieri-Gonzaga A, et al. (1998) Biologic activity of tamoxifen at low doses in healthy women. $J$ Natl Cancer Inst 90, 1461-1467.

DeLellis K, Rinaldi S, Kaaks RJ, Kolonel LN, Henderson B \& Le Marchand L (2004) Dietary and lifestyle correlates of plasma insulin-like 
growth factor-I (IGF-I) and IGF binding protein-3 (IGFBP-3): the multiethnic cohort. Cancer Epidemiol Biomarkers Prev 13, 1444-1451.

Giovannucci E, Pollak M, Liu Y, Platz EA, Majeed N, Rimm EB \& Willett WC (2003) Nutritional predictors of insulin-like growth factor I and their relationships to cancer in men. Cancer Epidemiol Biomarkers Prev 12, 84-89.

Holly J (1998) Insulin-like growth factor-I and new opportunities for cancer prevention. Lancet 351, 1373-1375.

Holmes MD, Pollak MN, Willett WC \& Hankinson SE (2002) Dietary correlates of plasma insulin-like growth factor I and insulin-like growth factor binding protein 3 concentrations. Cancer Epidemiol Biomarkers Prev 11, 852-861.

Kaaks R (1996) Nutrition, hormones, and breast cancer: is insulin the missing link? Cancer Causes Control 7, 605-625.

Kaaks R, Toniolo P, Akhmedkhanov A, Lakanova A, Biessy C, Dechaud M, Rinaldi S, Zefensuch-Jacqestte S, Shore RC \& Riboli E (2000) Serum Cpeptide, insulin-like growth factor (IGF)-I, IGF-binding proteins, and colorectal cancer risk in women. J Natl Cancer Inst 92, 1592-1600.

Key TJ, Sharp GB, Appleby PN, Beral V, Goodman MT, Soda M \& Mabuchi K (1999) Soya foods and breast cancer risk: a prospective study in Hiroshima and Nagasaki, Japan. Br J Cancer 81, 1248-1256.

Khalil DA, Lucas EA, Juma S, Smith BJ, Payton ME \& Arjmandi BH (2002) Soy protein supplementation increases serum insulin-like growth factor-I in young and old men but does not affect markers of bone metabolism. J Nutr 132, 2605-2608.

Maskarinec G, Franke AA, Williams AE, Hebshi S, Oshiro C, Murphy SP \& Stanczyk FZ (2004a) Effects of a 2-year randomized soy intervention on sex hormone levels in premenopausal women. Cancer Epidemiol Biomarkers Prev 13, 1736-1744.

Maskarinec G, Robbins C, Riola B, Kane-Sample L, Franke A \& Murphy S (2003) Three measures show high compliance in soy intervention among premenopausal women. $J$ Am Diet Assoc 103, 861-866.

Maskarinec G, Singh S, Meng L \& Franke AA (1998) Dietary soy intake and urinary isoflavone excretion among women from a multiethnic population. Cancer Epidemiol Biomarkers Prev 7, 613-619.

Maskarinec G, Takata Y, Franke AA, Williams AE \& Murphy SP (2004b) A 2-year soy intervention in premenopausal women does not change mammographic densities. J Nutr 134, 3089-3094.
Maskarinec G, Takata Y \& Kaaks R (2005) The relation between nutritional factors and insulin-like growth factor-I in premenopausal women of different ethnicity. Eur J Nutr 44, 105-113.

Nagata C, Shimizu H, Takami R, Hayashi M, Takeda N \& Yasuda K (2003) Dietary soy and fats in relation to serum insulin-like growth factor-1 and insulin-like growth factor-binding protein-3 levels in premenopausal Japanese women. Nutr Cancer 45, 185-189.

Renehan AG, Zwahlen M, O'Dwyer ST, Shalet SM \& Egger M (2004) Insulin-like growth factor (IGF)-I, IGF binding protein-3, and cancer risk: systematic review and meta-regression analysis. Lancet 363, 1346-1353.

SAS Institute Inc (2002) SAS Online Doc, version 8 Cary, NC: SAS Institute Inc.

Shu XO, Jin F, Dai Q, Wen W, Potter JD, Kushi LH, Ruan Z, Gao YT \& Zheng W (2001) Soyfood intake during adolescence and subsequent risk of breast cancer among Chinese women. Cancer Epidemiol Biomarkers Prev 10, 483-488.

Vrieling A, Voskuil DW, Mesquita HB, Kaaks R, Noord PA, Keinan-Boker L, Gils CH \& Peeters PH (2004) Dietary determinants of circulating insulin-like growth factor (IGF)-I and IGF binding proteins $1,-2$ and -3 in women in the Netherlands. Cancer Causes Control 15, 787-796.

Wangen KE, Duncan AM, Merz-Demlow BE, Xu X, Marcus R, Phipps WR \& Kurzer MS (2000) Effects of soy isoflavones on markers of bone turnover in premenopausal and postmenopausal women. $J$ Clin Endocrinol Metab 85, 3043-3048.

Wu AH, Stanczyk FZ, Seow A, Lee HP \& Yu MC (2002a) Soy intake and other lifestyle determinants of serum estrogen levels among postmenopausal Chinese women in Singapore. Cancer Epidemiol Biomarkers Prev 11, 844-851.

Wu AH, Wan P, Hankin J, Tseng CC, Yu MC \& Pike MC (2002b) Adolescent and adult soy intake and risk of breast cancer in Asian-Americans. Carcinogenesis 23, 1491-1496.

Yamamoto S, Sobue T, Kobayashi M, Sasaki S \& Tsugane S (2003) Soy, isoflavones, and breast cancer risk in Japan. J Natl Cancer Inst 95, 906-913.

Yu H \& Rohan T (2000) Role of the insulin-like growth factor family in cancer development and progression. $J$ Natl Cancer Inst 92, $1472-1489$.

Yuan JM, Wang QS, Ross RK, Henderson BE \& Yu MC (1995) Diet and breast cancer in Shanghai and Tianjin, China. Br J Cancer 71, 1353-1358. 